\title{
Alternancia Eléctrica
}

\author{
Antonio Ruiz Serrano ${ }^{a}$, Juan Carlos Ibáñez Torres ${ }^{b}$, \\ José Luis Polo Espinosa ${ }^{b}$, José Luis del Burgo Fernández ${ }^{a}$
}

\begin{abstract}
a Médico de Familia. Tutor de Residentes. Centro de Salud de Porzuna (Ciudad Real).

${ }^{b}$ R-4 Medicina Familiar y Comunitaria. Centro de Salud de Porzuna (Ciudad Real).
\end{abstract}

Correspondencia: Antonio Ruiz Serrano, Centro de Salud de Porzuna, 13120 - Porzuna, Ciudad Real, España.

Telf.: 926780541 , e-mail: aruizs@meditex.es.

Recibido el 14 de diciembre de 2009 .

Aceptado para su publicación el 4 de enero de 2010.

\section{RESUMEN}

Una de las causas de la alternancia eléctrica (AE) en el electrocardiograma (ECG) es el bamboleo u oscilación mecánica del corazón en el saco pericárdico cuando existe un derrame pericárdico más ó menos amplio.

Aunque la presencia de la $\mathrm{AE}$ en los derrames pericárdicos está referenciada en el cuadro clínico, puede pasar desapercibida, por lo que es importante pensar en ella para no pasar por alto los casos de sintomatología inespecífica y poco expresiva, ya que el taponamiento cardiaco puede poner en riesgo la vida del paciente. Además de los signos clínicos clásicos, el uso de la ecocardiografía básica en Atención Primaria puede ayudar al diagnóstico Palabras clave. Alternancia Eléctrica, Derrame Pericárdico, Electrocardiografía.

\section{ABSTRACT}

\section{Electrical alternans}

One of the causes of electrical alternans (AE) in the electrocardiogram (ECG) is the swaying or mechanical oscillation of the heart in the pericardial sac when there is pericardial effusion.

Although $\mathrm{AE}$ is one of the symptoms of pericardial effusion it could go unnoticed. It is important, therefore, to bear it in mind so as not to overlook non-specific, poorly expressed symptoms, because cardiac tamponade may be life threatening for the patient. In addition to the classical clinical signs, the use of basic echocardiography in Primary Care could help with the diagnosis.

Key words. Electrical Alternans, Pericardial Efusión, Electrocardiography.

\section{INTRODUCCIÓN}

La alternancia eléctrica cardiaca $(\mathrm{AE})$ consiste en una variación latido a latido del contorno y/o del tamaño de la onda P, del complejo QRS, del segmento ST y/o de la onda T. Las causas habituales de AE incluyen derrames pericárdicos, intoxicaciones por fármacos, alteraciones electrolíticas, isquemia miocárdica aguda y taquiarritmias ${ }^{1,2,3}$. También se ha descrito la $A E$ en relación con el neumotórax a tensión ${ }^{4,5}$.

Entre las causas descritas, la relacionada con derrame pericárdico ó taponamiento cardíaco está ampliamente referenciada en la literatura, en hasta un $10-20 \%$ de los $\operatorname{casos}^{4}$, habiéndose descrito como una tríada frecuente en el mismo la presencia de taquicardia sinusal, bajos voltajes del QRS y la mencionada $\mathrm{AE}^{4}$.

La presencia de líquido pericárdico hace que el miocardio se acerque ó aleje de la pared torácica y por tanto de los electrodos que registran la actividad eléctrica. Cuando el derrame pericárdico es abundante puede haber un excesivo movimiento del corazón dentro del saco pericárdico y debido a ello el corazón no recupera su posición original antes de la siguiente despolarización eléctrica, por lo que el eje del complejo QRS varía, apareciendo la AE en el electrocardiograma ${ }^{6,7}$.

\section{OBSERVACIONES CLÍNICAS}

Varón de 75 años de edad que acudió de urgencia al Centro de Salud (CS) refiriendo disnea de unas 12-24 horas de evolución, sobre todo al acostarse. No 
refería dolor torácico ni cortejo vegetativo, así como tampoco fiebre, edemas periféricos ni dolor en los miembros inferiores en los días previos. Como antecedente destacable había presentado un síndrome coronario agudo (SCACEST) infero-posterior un mes antes, que cursó con parada cardiorrespiratoria y que fue revertido con éxito con desfibrilador. En el informe de alta hospitalaria se reseñaba en el ECG la presencia de un ventrículo izquierdo de tamaño normal, con hipertrofia de paredes anterior y posterior, hipocinesia posterobasal y acinesia inferobasal. La fracción de eyección era del $53 \%$ y las válvulas cardiacas normales, sin hacer mención de derrame pericárdico ni de compromiso hemodinámico alguno. Se le implantó stent convencional sobre CD y otro sobre la DA por presentar lesiones obstructivas superiores al $70 \%$ a dicho nivel.

La exploración en urgencias del CS mostró un paciente estable, con ligera disnea en reposo, sin taquipnea. La auscultación cardiaca era rítmica a unos 100 latidos por minuto, sin soplos ni roces. La auscultación pulmonar no presentaba crepitantes y la saturación de oxígeno con pulsioximetría era del $97 \%$.

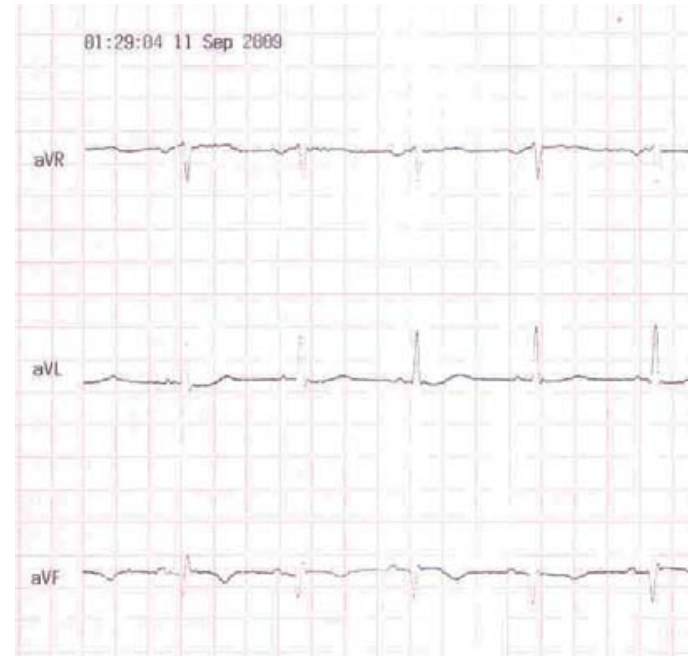

Figura 1. Alteraciones de la repolarización, onda T negativa en cara inferior y discreta alternancia eléctrica de la onda $\mathrm{T}$.

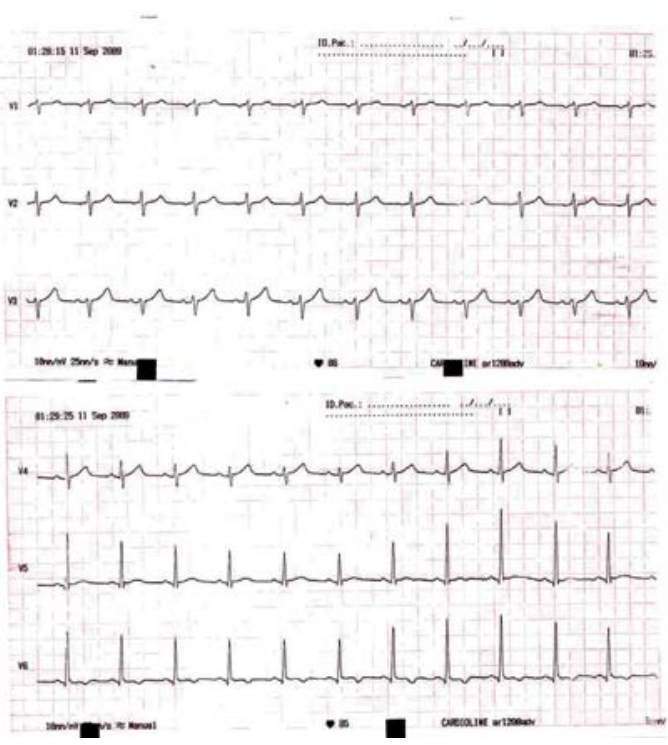

Figura 2. Alternancia eléctrica en derivaciones precordiales del complejo QRS y de la onda T.

El ECG mostró (figuras 1 y 2 ) un ritmo sinusal a 85 latidos por minuto, con alteraciones de repolarización en la cara inferior, con onda T negativa en II, III y aVF, aplanamiento de T en cara lateral y punta y cambios de voltaje en el complejo QRS en cara inferior, más evidentes en precordiales izquierdas (V4, V5 y V6), es decir, alternancia eléctrica.

Se le realizó ecocardiograma en el Centro de Salud con una sonda microconvex de 3,5 Mhz donde se apreció derrame pericárdico anterior al ventrículo derecho que no provocaba colapso diastólico de cavidades derechas ni compromiso hemodinámico (figura 3).

\section{COMENTARIOS}

La $A E$ es una alteración a menudo sutil del ECG, que hay que conocer para poder identificar y sospechar un derrame pericárdico de cuantía al menos moderada, como causa más frecuente, y así poder evaluarlo para poder actuar en función de su repercusión clínica.
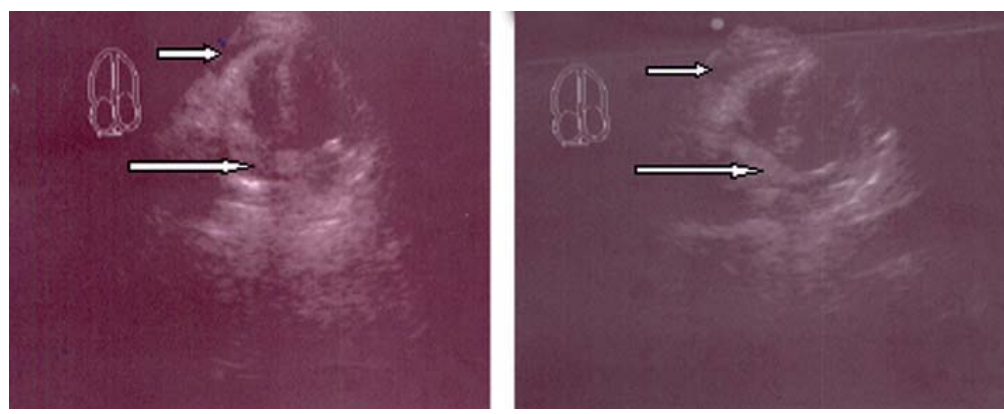

Figura 3. Derrame pericárdico en las dos imágenes (flechas) en corte apical de 4 cámaras. 
En nuestro caso, se trata de un síndrome de Dressler, que cursó con ligero-moderado derrame pericárdico, sin derrame pleural asociado, y sin datos clínicos de taponamiento cardiaco, lo que hubiera exigido una pericardiocentesis evacuadora ${ }^{6}$. La búsqueda y confirmación del derrame pericárdico puede hacerse en Atención Primaria mediante ecocardiografía básica con un entrenamiento mínimo.

\section{BIBLIOGRAFÍA}

1. Surawicz B, Fish C. Cardiac alternans: diverse mechanisms and clinical manifestations. J Am Coll Cardiol. 1992; 20:48399.
2. Valentín Segura V, Boix Ruíz JH, Peris Aguirre L, Cervera Montes M, Bertolín Guillem V, Colomer Terres MJ et al. Electric alternance of the T wave and torsade de pointes. Rev Esp Cardiol. 1980; 33(6):633-8.

3. Ortega Carnicer J. Alternancia del segmento ST y de la onda T durante la isquemia miocárdica transmural. Med.Intensiva, 2007; 31(3):156-9.

4. Ortega-Carnicer J, Giant R. Wave, convex ST segment elevation, and negative $\mathrm{T}$ wave during exercice treadmill test. $\mathrm{J}$ Electrocardiol. 2004: 37:231-6.

5. Marín Ortuño F, Oliver Navarrete C. Corazón Oscilante. Rev Esp Cardiol. 2002; 55(3):303.

6. Hoit B. Pericardial disease and pericardial tamponade. Crit Care Med 2007; 35(8):355-64.

7. Goldberger Zachary D, Loge Anna S. Three's Company: An inusual Clue. Am J of Med. 2008; 121(9):774-6. 